\title{
SOME NEW INEQUALITIES SIMILAR TO HILBERT-TYPE INTEGRAL INEQUALITY WITH A HOMOGENEOUS KERNEL
}

\author{
VANDANJAV ADIYASUREN AND TSERENDORJ BATBOLD
}

Abstract. In this paper, we establish some new inequalities similar to Hilbert-type integral inequality, whose kernel is the homogeneous function and the best constant factors are also derived.

Mathematics subject classification (2010): 26D15.

Keywords and phrases: Hilbert's inequality, Hölder's inequality, Hardy's inequality, Fubini's theorem.

\section{REFERENCES}

[1] G. H. Hardy, J. E. Littlewood and G. Polya, Inequalities, Cambridge University Press Cambridge, 1952.

[2] D. S. Mitrinović, J. E. PeČArić And A. M. Fink, Inequalities Involving Function and Their Integrals and Derivatives, Kluwer Acadamic Publishers, Boston, 1991.

[3] B. YANG, A New Hilbert-Type Integral Inequality and Its Generalization, Journal of Jilin University, 43, 5 (2005), 580-584.

[4] W. ZHONG, The Hilbert-Type Integral Inequalities With a Homogeneous Kernel of $-\lambda$-Degree, Journal of Inequalities and Applications Vol. 2008, Article ID 917392, 12 pages, 2008.

[5] M. KRniĆ And J. PeČARIĆ, General Hilbert's and Hardy's Inequalities, Math. Inequal. Appl. 8 (2005), 29-51.

[6] M. Krnić, G. Mingzhe, J. PeČArić And G. Xuemei, On The Best Constant in Hilbert's Inequality, Math. Inequal. Appl. 8, 2 (2005), 317-329.

[7] I. Perić And P. Vuković, Hardy-Hilbert's Inequality With General Homogeneous Kernel, Math. Inequal. Appl. 12 (2009), 525-536.

[8] N. Das and S. SAhoo, New Inequalities Similar to Hardy-Hilbert's inequality, Turk. J. Math. 34 (2010), 153-165.

[9] N. Das And S. SAhoo, On a Generalization of Hardy-Hilbert's Integral Inequality, Bul. Acad. Sţiinţe Repub. Mold. Mat 2 (2010), 91-110.

[10] W. T. Sulaiman, On Two New Inequalities Similar to Hardy-Hilbert's Integral Inequality, Int. J. Math. Anal. 4, 37-40 (2010), 1823-1828.

[11] W. T. Sulaiman, On Three Inequalities Similar to Hardy-Hilbert's Integral Inequality, Acta Math. Univ. Comenianae LXXVI, 2 (2007), 273-278.

[12] W. T. Sulaiman, On Two New Inequalities Similar to Hardy-Hilbert's Integral Inequality, Soochow J. Math. 33 (2007), 497-501.

[13] H. Du And Y. MiaO, Several New Hardy-Hilbert's Inequalities, Filomat 3 (2011), 153-162. 